En el contexto de invisibilidad de la arquitectura peruana de la mitad del siglo $X X$, tanto en libros como en debates y en exposiciones, este catálogo responde a una necesidad fundamental. Solo el legado prehispánico y virreinal tiene el favor de los turistas, y el vértigo patrimonicida de la política ultraliberal de los últimos 20 años va desapareciendo tanto balcones como huacas. Por otro lado, el mundo ha vivido cuatro décadas de campaña de descrédito de la arquitectura moderna en tanto que asociada a la industrialización de la vivienda, la mecanización de la vida y, para los más entendidos, el relato progresista ilustrado. Sin embargo, es posible observar desde unos años cierta rehabilitación de la forma moderna, en cuanto sea desarticulada del programa emancipador que la inspiró. Acaban de homenajear a Kenneth Frampton en la Bienal de Arquitectura de Venecia, más reconciliada con el ideario moderno. En el Perú, recién se está creando archivos y exposiciones de arquitectura moderna en universidades privadas, gracias al impulso de Humberto Viccina en la Universidad de Piura, Paulo Dam en la Pontificia Universidad Católica del Perú (PUCP) y Enrique Bonilla en la Universidad de Lima. Alejandra Acevedo, nieta de Jorge de los Ríos, y Michelle Llona, hija de Miguel Ángel Llona, co-curadora de una exposición sobre arquitectura moderna en la Galería Municipal Pancho Fierro en 2013 y flamante directora del Archivo de Arquitectura PUCP, cuentan entre sus fervientes defensoras.

Este catálogo es un primer intento de identificar objetos y proyectos esparcidos por el país. Tres años son poco para afrontar la dispersión de los archivos; no queda casi nada de las maquetas ni los dibujos de los proyectos del Estado. Las dos arquitectas se dieron el trabajo colosal de redibujar la planimetría de más de 200 edificios, loable esfuerzo que cumplió con el objetivo principal, dictado por el historiador García Bryce, de informar al Ministerio de Cultura para que considere los edificios modernos como monumentos a proteger. He ahí el acto más comprometido a la fecha a favor de la conservación del patrimonio moderno en el Perú, mientras se sigue demoliendo edificios de Seoane, Villarán, Rodrigo $y$, pronto, Linder.

Hace año y medio que se publicó, y el libro ya es de uso mandatorio para los

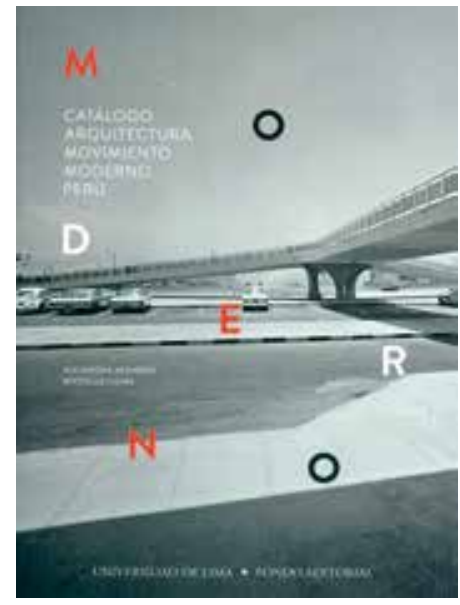

\section{CATÁLOGO ARQUITECTURA MOVIMIENTO MODERNO PERÚ} MICHELLE LLONA Y ALEJANDRA ACEVEDO

FONDO EDITORIAL UNIVERSIDAD DE LIMA, LIMA, 2016.

RESEÑA DE PATRICIA CIRIANI ESPEJO estudiosos de la arquitectura limeña, y la mejor guía para los arquitectos del mundo entero. Seguro se agotará muy pronto y necesitará una reedición. Entonces se beneficiaría de una numeración unificada de los planos, textos y mapas, así como de una concentración en un solo mapa de los edificios para todo Lima.

Con gran generosidad, las autoras multiplicaron las formas gratuitas de acceder a sus investigaciones, con una página web que contiene más análisis de obras que el mismo libro y una aplicación móvil gratuita (CAMMP) muy cómoda, de búsqueda cruzada.

De los 448 edificios recomendados por arquitectos e historiadores, las autoras seleccionaron solo 60 , sin precisar sus razones. Se extraña la ausencia de los primeros edificios de Málaga y del colegio Humboldt de Linder. De la misma manera que se valora la planta libre de Miró Quesada o de Bianco, valdría la pena distinguir aquellos aportes tipológicos tan preciados por la racionalidad moderna, como la introducción del dúplex en la vivienda social peruana por Ciriani (2a etapa de las tres Unidades Vecinales). La autoría también es un tema relevante, y el libro confunde a veces conceptores y colaboradores (FAUA UNI, Residencial San Felipe).

En un justo homenaje al arquitecto, diputado, decano y presidente de la República, Fernando Belaúnde Terry, se seleccionaron los proyectos de mayor envergadura. Además, este libro apuesta por reproducir los artículos de su revista El Arquitecto Peruano, en su mayoría descriptivos: falta contra- ponerles una voz más crítica o teórica para ubicar la arquitectura peruana en la modernidad mundial.

Las mismas autoras muestran una perspectiva restringida del Movimiento Moderno. Su texto introductorio menciona la modernidad como un periodo histórico que culmina en 1965, sin explicar por qué no se consideró el periodo brutalista del gobierno militar de Velasco, por ejemplo, ni recordar la causa común del racionalismo que unía a sus promotores. Aquel ímpetu de progreso del proyecto moderno que el filósofo alemán Jürgen Habermas consideraba todavía inacabado en 1980, una causa que el texto de Elio Martuccelli sí menciona, en un tono ameno y personal que contrasta con las descripciones del libro.

El testimonio de Adolfo Córdova, por su lado, aporta el componente político esencial para relacionar la modernidad con el desarrollo industrial del país y el progresismo político. Pues en Perú como en el resto del mundo, esta ha implicado la realización de programas públicos de viviendas, planos urbanos, casas modelos y edificios privados orientados a resolver problemáticas públicas; por lo tanto, no se la puede desligar de la historia política y económica del país, ni del bienestar social que emulaba.

Esperamos con impaciencia la próxima edición, con el resto de los 448 proyectos, y contamos con que se pueda extender el catálogo más allá del 1965. 